\title{
Pre-service Mathematics and Physical Education Teachers' Perceptions of using Play-based Teaching Strategy across the Foundation Phase
}

\author{
Blanche Ntombizodwa Ndlovu \\ University of Free State, Bloemfontein Campus, South Africa \\ https://orcid.org/0000-0002-3506-7382 \\ Dumsani Wilfred Mncube* \\ University of Zululand, KwaDlangezwa, South Africa \\ https://orcid.org/0000-0001-5566-2288
}

\begin{abstract}
This qualitative case study explores early childhood pre-service educators' perceptions of using play-based teaching strategy across the Foundation Phase. A play-based approach promotes a special mode of thinking, sense of possibility, ownership, control, and competence in maths and PE learners. That is why scholars believe that hybrid pedagogical content knowledge that integrates play-based learning sustains learner attention throughout the lesson and promotes problemsolving skills. Therefore, the main objective of this study is to propose alternative pathways that promote the implementation of a hybrid pedagogical teaching strategy in the Foundation Phase. This study draws from a qualitative case study conducted at one of the universities in KwaZulu-Natal to explore the perception of pre-service teachers about using a play-based teaching strategy in pre-Grade $\mathrm{R}$ and Grade R classes. Five preservice teachers who teach both mathematics and PE were purposively and conveniently sampled to generate data using narratives and semi-structured interviews to describe their perceptions and experiences. Zoom group meetings and WhatsApp one-on-one semistructured interviews were used during the data generation process. The findings reveal that pre-service mathematics and PE teachers perceive play-based pedagogies as necessary to provide a wide range of opportunities for learners to learn to count, visualising groups, and problem-solving skills. They underscore the importance of drawing from a hybrid approach that draws strength from play-based learning to complement formal learning.
\end{abstract}

Keywords: foundation phase; mathematics; play; pre-service teachers; teaching strategy

\footnotetext{
* Corresponding author: Dumsani Wilfred Mncube; Email: MncubeD@unizulu.ac.za 


\section{Introduction}

Foundation Phase (FP) teaching needs to adapt to the realities of the $21^{\text {st }}$ century by systematically infusing a hybrid approach into pedagogy to strike a delicate balance between formal and play-based teaching. Indeed, early childhood education (ECE) teachers in South Africa aspire to popular discourse underpinned by a binary choice between, on the one hand, learning and school preparedness, and on the other, paying special attention to child-led play. Playbased teaching benefits learning when facilitated in the pre-Grade R and Grade R phases with the use of resources and teacher-facilitation approaches based on developmentally appropriate principles. Assurance of such a basic principle reinforces the popular belief that all learners, young and old, have a constitutional right to play as recognised in the Rights of the Child which South Africa ratified in 1995. This noble principle forms the basis of the Constitution against the backdrop that school curricula used to deprive learners of using play pedagogies to learn (Department of Basic Education [DBE], 2015; van Vuuren, Uitenbroek, van der Wal \& Chinapaw 2018; Isaacs, Roberts, Spencer-Smith, \& Brink, 2019).

In South African schools, there is a greater focus on strengthening teacher-led instruction in early childhood education (ECE) (Bubikova-Moan, Hjetland, \& Wollscheid, 2019). To this end, pre-service teachers are expected to safeguard children's appetite to constantly engage in a spontaneous and free play-aligned curriculum (Stebler, Vogt, Wolf, Hauser \& Rechsteiner, 2013). There is, however, growing concern regarding the dearth of literature and the alarming disappearance of play-based activities in pre-school practice (Bubikova-Moan et al., 2019). The DBE (2019) states that despite all good intentions to capacitate preservice teachers to focus on teaching and learning, there is no consensus on hybrid preschool pedagogy. Consequently, schools pay very little attention to the development of an ECE curriculum aligned to a play-based approach because it attracts controversy (Isaacs et al., 2019). Literature warns that such poor leadership threatens ECE practitioners inspired to implement a play-based approach for improving professional practice, indirectly stifling curriculum innovations for teachers. Van Vuuren et al. (2018) argue that FP educators understand that their curriculum aspiration towards play may remain unachievable (Stebler et al., 2013).

The National Integrated Early Childhood Development Policy (2015) developed by UNICEF outlines international protocol targeted towards helping ECE preservice teachers improve implementation of hybrid pedagogy in mathematics and PE. Zooming directly onto pre-service teachers' perceptions and contexts, this study seeks to understand how a play-based approach to teaching contributes to improvement in learner performance in mathematics and PE. The topic of preservice mathematics and PE teachers' perceptions is commonly discussed during teacher training as it constitutes a highly charged excitement for teacher trainees (Kalogiannakis, Nirgianaki \& Papadakis, 2018). In essence, educators consider playing as an add-on activity and as an expression of local indigenous people who try to promote their traditional social realities. This notion is challenged by CAPS, which champions play-based teaching strategy. By paying special attention to ECE teachers this study by no means excludes other voices, but it unpacks how 
their practice influences policy and children in both mathematics and PE classrooms.

\section{Literature review}

Over the years, a wide range of teaching approaches and teaching material has been developed to improve mathematical learning in early childhood education. A study conducted by Aronstam and Braund (2016) reveals the significance of play and games in encouraging language use as well as the personal development of both educators and learners in the school. Teaching through play requires a detailed planning procedure by including features that have a strong traditional orientation to teaching and learning, especially for FP learners. This is in contrast to literature that confirms that most educators and practitioners work in underresourced schools, and basic facilities are non-existent (Aronstam \& Braund, 2016). Educators' expectations in the FP need to be challenged to match the realities of each grade. School realities include the extent to which school leaders and professionals understand the role of learning through play as a concept. Sadly, many experienced educators dismiss pre-service educators when they integrate this innovation into their lessons.

\subsection{The international perspective on the play}

Studies show that countries in Southeast and East Asia are currently transforming pedagogy from a traditional didactic approach to a constructivist approach (Barnard \& Braund, 2016). At the heart of this shift is the need for innovative practices driven by a range of skills, including social, emotional, physical and cognitive skills (Parker \& Thomsen, 2019). More importantly, the global policy shift towards educational outcomes reflects this notion. Global institutions such as the United Nations and its Sustainable Development Goals have pushed for a high-quality education to foster learners' holistic development (UNICEF, 2018). This recognition has been the culmination of research that has demonstrated the value of prioritising holistic skills development such as play. The study by Kalogiannakis et al. (2018) identified a sudden shift in many educational programmes to involve skills, metacognition, and collaboration in an attempt to impact positively on learner achievement. Some authors seem to suggest formal in the ECE curriculum, however, questioned its heavy reliance on the instructional learning approach within this phase. Overloading early childhood education curriculum with content knowledge is likely to have undesirable effects in the early years of child development.

Western theories of development have also promoted play in the curriculum to address this missing parameter. Berkvens, Kalyanpur, Kuiper, and van den Akker (2012) argue that teaching and learning material alone is never sufficient in any learning environment. They found that playfulness in early mathematics and PE has positive effects at the beginning of primary school. These learners stand out because they have benefited from a child-centred and play-based learning environment. Kalogiannakis et al. (2018) believe that play-based teaching inspires both educators and learners to be creative and sensitive to the needs of the learners by encouraging the co-creation of learning resources within their reach. The point of departure here is that cognitive and emotional intelligence is linked to 
professional development when the resource is useful. Aronstam and Braund (2016) propose the use of games to improve the teaching of number skills, patterns that are likely to inspire confidence during mathematics and PE learning. He sees the role of the facilitator as a designer and selector of appropriate learning materials who only use appropriate learning activities. Isaacs et al. (2019) argue that appropriate learning activities should also accommodate educators and their teaching styles to achieve the desired results. Barnard \& Braund (2016) reveal that although teaching via lectures which involve the whole class dominates, other instructional activities, examined for their effectiveness for educators' understanding and engagement, proved effective.

\subsection{Play-based approach as a teaching method}

Play-based learning is one of the powerful instruments for early childhood teachers to activate self-directed learning. The study by UNICEF (2018) shares the view that early childhood learners show better learning outcomes when their formal learning is characterised by a play-based approach rather than by heavily loaded instructional and formal teaching (Parker \& Thomsen, 2019). Most studies praise the hybrid approach specifically for both mathematics and PE because it not only promotes formal learning and instructional teaching but also emphasises the significance of play-based teaching and learning (Aronstam \& Braund, 2016). Kalogiannakis et al. (2018) caution early childhood teachers about assuming that play could be the panacea for all the challenges facing the teaching of mathematics. Instead, they recommend a good balance in the curriculum in the ECE learning for teachers. In essence, meaningful teaching strategies are an absolute necessity considering the amount of planning needed to select relevant games for play-based teaching and learning in mathematics and PE.

The teacher plays a vital role when play is organised within the classroom environment. He/she must plan and initiate playing parameters and be prepared to act as an observer (Kalogiannakis et al., 2018). This generalisation was expressed by Aronstam and Braund (2016) in noting that play-based teaching strategies are available as ice-breakers during the planning stage of the lesson. More importantly, play as teaching pedagogy affords teachers ample opportunity to observe individual learners use the material and decide on the right course of action while asking probing questions. Parker and Thomsen (2019) remind early childhood teachers how powerful play-based teaching strategies might be to achieve their end-game, but they must remember that learners have their hidden purposes; they must be allowed to express them and get the first-hand experience without the supervision of the teacher.

Bubikova-Moan et al. (2019) highlights three different approaches for educators teacher-centred, content-centred and learner-centred - which involve play and also classifies learners' strengths and weaknesses. The expert understanding of using play lies in educators' understanding of the subject's objectives. Kalogiannakis et al., (2018) thinks teaching resources are important in teaching and learning in the FP. FP educators need specific teacher/learning aids to make teaching easier (DBE, 2013). Practical activities play a clear role in aiding learners' development in mathematics and PE. Modelling numbers in the classroom 
seemed to develop imaginary counting strategies, and can then work with what learners believe in learning situations. This shows that young learners are capable of imagining objects when they are encouraged to use play and games in the learning process. Isaacs et al. (2019) argue that practical work alone does not translate into teaching and learning in the classroom, but needs to be coupled with some play-based learning to leave a long-lasting impression. The young learners normally link audio-images (i.e. sounds or rhythms) to a concrete image of something meaningful, such as fingers or objects.

Visual and tactile images, such as an abacus or bead string, assist learners in linking counting to movement. These artifacts are a useful mathematical resource for counting and visualising groups. Teachers allow learners to play with beads and an abacus while counting in tens (Kalogiannakis et al., 2018). Dewey (1933) asserts that the use of maths and PE resources provides an environment that transforms learning spaces. Parker and Thomsen (2019) found that long-term use of play-based learning had a positive effect on learners' achievement, by allowing them to use concrete objects to observe, model and internalise abstract concepts. These factors individually and collectively influence the implementation of an innovative curriculum.

\section{Vygotsky's theorisation of play-based learning}

This study is underpinned by Vygotsky's (1978) theory of cognitive constructivism, which seeks to support the shift towards a play-based learning experience. A teacher and children should always be exposed to the surrounding environment as part of knowledge construction. The research reveals that lessons foregrounded in play-based pedagogy present endless opportunities associated with play experience from interaction with the environment. The benefit transcends theoretical disposition by deepening the value of collaboration and improving critical skills. Vygotsky foresaw the danger associated with rote learning and mechanical tasks and began to explore a new trajectory and opportunities to allow participation in learning activities within the environment.

Several studies argue that most children grow and develop because of social interactions instead of a linear process. Once exposed to the zone of proximal development (ZPD), they gain new understanding, realities, and abilities (Nugent, 2017). The research supports these stages as premised on the learner's ability to operate independently, against the level which the child can reach with adult support or assistance from capable peers. Learning, according to the ZPD, is managed for new learning to take place at a rate that is meaningful for learning to occur. The study conducted by Nugent (2017) in America states that pretend play experiences provide a means for this developmental change to occur, as children work together to complete a task that they could not have completed without the scaffolding that results from interaction with more capable peers.

\section{Research objective}

The main objective of this research was to explore pre-service educators' perception of teaching mathematics and PE using play as a teaching resource. The 
perception includes how tools, resources and ideas are used to implement playbased education during their teaching practice were explored.

\section{Research questions}

- What are the mathematics and PE pre-service educators' perception of using play as a teaching strategy?

- How do mathematics and PE pre-service educators use play as a teaching strategy?

\section{Research methodology}

The study employed a qualitative research method underpinned by an interpretive qualitative case study of five pre-service teachers who were purposively and conveniently selected based on their accessibility, willingness to share their perceptions, and experiences gained during teaching practice in various schools. Ethical clearance was granted by the research office. All participants were requested to read and sign consent forms (i.e. forms containing detailed information about potential ethical issues, including confidentiality, anonymity, and beneficence). Participation was voluntary, and anonymity was guaranteed by using pseudonyms to conceal the identity of the pre-service teachers. All five processes used in maintaining trustworthiness were observed in this study: credibility, conformability, dependability, triangulation, and transferability (Yin, 2014). Interpretivism was used to understand and describe the perception of pre-service teachers in infusing play-based pedagogy when teaching mathematics and PE. Yin (2014) argues that an explorative case study design generates a rich and deep description of teachers' perceptions, which results in the reinforcement of play-based pedagogical practice as a gold standard for the teaching of mathematics and PE.

Haegele, Hodge and Shapiro (2020) argue that narrative inquiry begins with an ontology of experience grounded in Dewey's theory of experience, conceptualising reality as relational, temporal, and continuous. The data generation process was guided by two phases. The first phase involved semistructured interviews generated from pre-service educators shortly after the end of teaching practice, using open-ended questions. This phase was guided by a series of questions asked about their perceptions of using a play-based approach in FP teaching. The second phase of data collection used narratives produced by pre-service teachers over the second semester (four weeks of teaching practice and lectures). Participants reflected on their practical observations during lesson presentations that integrated play-based learning. Triangulation ensured dependability by using various methods of data generation, such as narratives and semi-structured conversations (Cohen, Manion \& Morrison, 2011).

Data were analysed using content analysis. Raw data were refined into words and themes drawn from the interpretation of results. Specifically, latent content analysis was preferred owing to its strong interpretive approach to finding underlying the meaning of a text - what the text is talking about. Generated data emerged from two research instruments which were first coded for easy transcription, and to avoid possible loss of meaning. The researcher later put 
mapped codes into categories to link the theoretical framework with literature to improve alignment with themes. In the final analysis, three main focused themes emerged as a guiding process for the presentation of findings.

This article was guided by two main research questions, namely: what pre-service mathematics and PE teachers' perceptions of play-based teaching strategy across the FP are, and why their perceptions take particular forms when play is used as a hybrid teaching approach. The next section presents findings and discussion based on the two main research questions and proposed alternative solutions are presented to demonstrate what pre-service teachers recommended, and what inspired them to use play-based teaching as a hybrid approach for teaching mathematics and PE in the FP.

\section{Findings and discussion}

This section presents the results from both the semi-structured interviews and narrative inquiry. The purpose of this study was to understand pre-service educators' perception in the FP grades when play is used during teaching and learning. The outcome was that pre-service educators perceive hybrid approach as an important pedagogical teaching strategy for harnessing foundation skills and attitudes when integrated play-based pedagogy. It was important to track the progress in teaching experience gained from teaching using play in rural schools and to explore whether resource provision matches the curriculum requirements. The participants reflected extensively on how much progress has been made, and how much still needed to be done to bridge resource allocation. More importantly, this study proposed intensification of using play alongside teaching to achieve the intended outcomes of the FP curriculum.

\subsection{Pre-service educators' perceptions of play-based approach in the FP}

Participants have an understanding of how a play should be used during a teaching in the FP: what fell within the categories of the nature of play, its benefit, challenges, the opportunities for play at school, and why they think the play is possible in many schools in South Africa. Most participants saw the play as an educational tool for teaching across subjects, including mathematics and PE, while two participants were not convinced, and described the play as a free activity. The play was seen as organised chaos, fun, and regarded as a structured activity guided by sets of rules and regulations.

Mrs. Dlomo: In my understanding, the play does appear to be a powerful expression that can be formalised and can occur in a natural setting based on rehearsed routines targeting skills and endurance. Some of the skills could be counting, organising patterns, building structures, etc.

Play gives young learners the ability to experiment with new ideas in a space and to learn from these, individually and collectively, how to perfect activities. In a narrative report, learners were grouped to play with beads where counting was promoted through groupings and arrangements. In class, participants identified certain groups of learners who learn better when they are in play mode, while others need guidance from their mentor. The pressure that comes with the curriculum schedule deprives certain groups, while others benefit. The issue of 
play was identified as a necessity to improve problem-solving within the curriculum implementation and enhance teaching and learning.

Most of the participants indicated that they now understood why ECE children need to learn by play. At their age, learners would like to touch objects to understand what would happen while they develop the confidence to play for fun and gain experiences based on trial and error. They benefit indirectly in acquiring physical, cognitive, creative, emotional, physical, and social skills (Parker \& Thomsen, 2019). The results also revealed that pre-service educators began to understand the significance of infusing play-based teaching into the lesson planning and building trust in their instincts while they engaged the learners in play.

Zondezi: Honestly, the play does something extraordinary to learners' confidence, and indirectly allows you to gain trust in learners' ability. It allows each teacher to devise groundbreaking teaching strategies that promote the hybrid approach to teaching. Play is fun and allows each one to express their feelings and gain more freedom and space to use their environment to their betterment. Trust helps me gain valuable knowledge from learners when playing in a formal setting. It was, however, more challenging to co-create these activities and relate them to the lesson of the day - but as a teacher, I had to take the best shot.

This point was consistently highlighted in the narrative inquiry, where participants wrote: "Using play has brought more light and more crazy stuff to my lesson fun. Learners enjoy some play because it is fun and full of interesting ideas, but at times they don't show any interest." The participants had to prove their worth to senior educators who were instrumental in guiding them during the implementation of the play-based lessons. Most participants praised the infusion of play into the content areas because content knowledge alone is never enough since it requires learners to operate on an abstract rather than practical and fun level. This result is consistent with the findings of Kalogiannakis et al. (2018) that the role of play should be aligned with curriculum delivery.

Obama: Teaching and learning that integrate play require a competent and dedicated teacher who understands the need to think critically about the relevance of play in the lesson, and link plays with assessment activities to understand the impact of play in the lesson. For example, I sometimes give them counters to play with, and later ask them to use the same play activity in a formal activity. This is an excellent approach.

The fact is that while play is fun, it needs to be taken seriously to have a positive impact on educational outcomes. Important pedagogical content knowledge of the play or game is mandatory to run a successful ECE classroom (Kalogiannakis et al., 2018). It is even more mandatory because mathematics is known to be a challenging subject, yet fun to many children; effort to engage learners in a practical and logical sequence is mandatory. The same views were expressed during the narrative inquiry: "Some maths activities are difficult for the learner when approached from a conceptual perspective, but the infusion of play-based activities helps educators to achieve learning outcomes more quickly." At the same time, it is necessary to understand certain rules for several games for a better explanation of rules and 
the reasoning behind the play before learners can engage in it. This ensures fairness and equal opportunity for all. A learner with learning challenges needs special attention, fair treatment, and equal opportunity if a play is to be used to enhance teaching and learning, as cautioned by a study conducted in Greece (Lenakakis, Howard, \& Felekidou, 2018). Furthermore, educators need to spend more time with every learner while relating play to the lesson and assessment (Mzimela, 2016). Most pre-service educators felt the significance of play in the learners' ability to organise themselves into small groups and show their full potential of using guided play techniques.

\subsection{Implementation of play-based education in the FP class}

It was important to ascertain the perceptions of the participants based on the specific content knowledge they investigated. Each was interviewed about their perceptions of the practical implementation of the play-based lessons taught during teaching practice. The first issue that drew their attention was the list of resources recommended for teaching FP mathematics lessons using play, as described earlier. In the actual implementation, participants first listed resources such as flashcards, shapes, counting charts, Unifixes, blue boards, play money, building blocks, boxes of different shapes, mathematics games, e.g., Ludo, snakes and ladders, jigsaw puzzles, dominoes, and tangrams, counters and cardboard circles (Stebler et al. 2013). These items were on the list of important resources recommended by the policy document for the implementation of a play-based lesson for mathematics. The first content area that was investigated to ascertain the perceptions of participants was operations and relationships. The second content area investigated comprised patterns, functions, and algebra. Not all content areas were investigated in this study owing to time constraints and the main focus of the study.

\subsubsection{Perceptions of pre-service teachers on using play to teach operations and relationships}

The outcome of the investigation reveals that most schools have only one or two of these critical resources for play-based learning. It was clear that certain schools recommended improvisation as they don't have enough resources. The Department of Basic Education in KwaZulu-Natal is failing these schools. According to participant Zondezi, schools should be forced to order all of these critical resources, or they should be supplied to each school, as some SMTs will not encourage teachers to order them.

Each participant was asked to focus on a specific content area covered in the FP, to present a fair reflection based on their experience. Their views shed light on their perceptions and experiences in each of these curriculum content areas.

The first two participants, Zondezi and Mtetwa, focused on numbers, operations and relationships:

Zondezi: My mentor was quick to work with me to analyse and identify content areas that should be covered by both free play outside and free play inside. This information was helpful to focus on the content area assigned to me, which was numbers operations and relationships. I first explored water and sand play learners were using during free play outside to learn 
addition and subtraction. While embarking on play with children outside the class, it was helpful to explain basic number operations to them in a fun and relaxed atmosphere using games...

Mtetwa: In my case, the senior educators assigned to me were helpful in first introducing me to all the resources available for FP classes, and second in helping me explore number operations and relationships with learners during the series of lessons. It was a very interesting experience to work with learners during a play session, and later assess them on this specific content area. For example, I taught them to count pictures of grouped objects up to 500, and read and write numbers from 0 to 1000 as part of number operations and relationships.

Most participants used free play outside as part of the teaching strategy. In this case, the main target was operations and relationships. The sand was used as the learners like to play outside, and it is readily available, while water was taken from a river. The little available potable water is kept for drinking and cooking for the school feeding scheme. The alignment of the university curriculum with a school-based curriculum should be mandatory. It was clear that some of the participants were not competent to handle certain aspects of the curriculum, and were not hesitant to leave out those sections.

Even though most learners enjoyed this strategy, a few struggled to understand the rationale for using sand and water as part of the lesson. The narrative report recorded certain activities that gave most learners problems: "Certain learners were unable to play with confidence during the sand and water activity. They were unable to demonstrate an understanding of operations and relationships during the assessment." This was evident when learners were assessed after the series of activities. In terms of free play inside the class, the participants also acknowledged its value during the lesson. Zondezi gave numerous examples here:

The class used specific play that addressed operations and relationships. Games such as toys and blocks were used, but owing to the shortage, it was difficult to assess their effectiveness. I do not doubt that if these resources were available in numbers, learners would have benefited tremendously. Those learners who were able to lay their hands on these resources were able to understand operations and relationships as they performed better during the assessment.

In this content area, the participant was satisfied with the pedagogical aspect of play in the curriculum. She highlighted the complexity of play-based learning and the fact that her professional knowledge was enhanced during the implementation of play in the classroom. The ability of this participant to combine the pedagogy behind the play with the content area enhanced most of the lessons, and this finding is consistent with what Isaacs et al. (2019) found in their study. They revealed that successful educators are versatile and dynamic players, who always demonstrate a superior understanding of integrating pedagogy and content knowledge in class. The CAPS curriculum is very clear about what needs to happen in the FP during play (either free play outside or free play inside the class) to achieve critical learning outcomes. 


\subsubsection{Perceptions on using play to teach patterns, functions and algebra}

The rest of the participants were assigned to share their perceptions about the use of play during the teaching of patterns, functions and algebra. Activities could be solving basic equations, two-step or three-step equations, equations with variables on both sides, and mixed equations. The shortage of resources was an issue from the beginning of the interviews, and improvisation took place during the lesson to infuse play within the content area. This challenge was also underlined in the narrative report, and patterns and functions were used to analyse the perceptions of pre-service educators, but algebra was not explored. This participant found the nature of the content area to be challenging:

Mtetwa: I must admit that this content area involving patterns, functions, and algebra was complex to explore. First, it is very much easier to infuse play during the teaching of patterns to young learners. Fortunately, blocks were enough for all the learners to draw lines, shapes, and objects.

However, this was not all that these participants identified when they integrated play into their lesson planning and presentation. They could explain their role that changed their perceptions of the children's play:

Mtetwa: For me, to listen attentively and offer minimal help (...) as a way of enhancing the quality of play changed my perception. Investigating how they are forming patterns gives me more information about their lived experiences before I can come in to help solve their problems. But listening to and observing what they are doing prepares me. Once they are introduced to the concept and communicate how it is done, their play-based learning will be achieved...

Mtetwa spent more time understanding how prior knowledge influences learners' engagement in games during practice. It enabled teachers to understand their limitations and improve their pedagogical philosophy where learners were struggling during play to guide learners in the future. Later, Mtetwa realised that learners were getting excited to use play as part of the lesson, and this is how she expressed her delight.

My learners were fascinated with this activity to show their skills and talent in front of others. I used this activity to develop their language and speaking skills by asking them to integrate the pattern they were making into the mathematics and PE lesson.

This activity taught learners to make two-and three-dimensional geometric shapes and objects by cutting out paper or cards; in other instances, they had to draw them as part of the play. The participant was able to experiment with the use of patterns by asking the learners to make patterns from box shapes and ball shapes that they had made from play-dough. The level of understanding was good, and participants were able to use play successfully in the lesson.

7. Conclusion and recommendations: Nurturing the child through play After careful analysis of results, numerous recommendations were made to improve the infusion of play into lessons. The CAPS document, which is the 
official policy document, needs to be revised to advise and guide teachers on how to use play-based learning to teach mathematical concepts to young children.

Teachers have a positive outlook on how the curriculum has been structured, and are allowed to use their creativity under CAPS. Play allows both teachers and learners to be flexible in using their creativity. Play is fun to plan, and learners are having fun while expressing their raw talent with a little guidance from the teachers. Participants noted that planning for play is complex, but has huge curriculum implications, as learners develop confidence and work in groups to achieve their tasks.

Rules and regulations guide how the play should be implemented to teach learners to respect their teammates and be disciplined. Participants revealed the steps taken by the DBE to systematically infuse play into mathematics lessons. This is done through imagining role-playing a particular career, renting and supplying an apartment, and negotiating other features of daily living. When learners use imagination and creativity to dramatise roles or situations, such as trying on roles and pretending to have possible careers, they are practising independence and taking on roles of power. Using their imaginations in these ways enables learners to be patient and persevere. One step was to identify important resources needed to ensure that play as a strategy is realised in the school calendar. Four main content areas were identified as the basis from which play is to be implemented in the FP curriculum, and possible scenarios were presented to guide teachers.

Finally, the results reveal that a play-based approach to teaching has the proven potential to improve intrinsic motivation to do mathematics as well as academic content, if that content is integral to the gameplay, such as the Great Race board game with embedded early mathematics learning. Pre-service mathematics and PE teachers are capable of implementing a hybrid approach to teaching these subjects. Teaching mathematics and PE in this way is effective, meaningful, interesting, contemporary, motivating, and particularly amusing. Based on the results, it is recommended that each content area be resourced properly to enforce equity across the schools, irrespective of socio-economic status. To this end, participants recommended that procurement strategy be centralised to cater for all schools to achieve resource equity. In terms of training, pre-service and inservice training should be evaluated in terms of training and content methodology to ensure that training is contextualised to include developmentally appropriate principles ensuring hybrid teaching takes place in the Foundation Phase.

\section{References}

Barnard, E., \& Braund, M. (2016). Strategies for the implementation of mathematics in grade R: Teachers' beliefs and practices. South African Journal of Childhood Education, 6(1), 1-8. https:// doi.org/10.4102/SAJCE.v6i1.409

Berkvens, J. B. Y., Kalyanpur, M., Kuiper, W., \& Van den Akker, J., (2012). Improving adult learning and professional development in a post-conflict area: The case of Cambodia. International Journal of Educational Development, 32, 241-251. https://doi.org/10.1016/j.ijedudev.2011.03.008 
Cohen, L., Manion, L., \& Morrison, K. (2013). Research methods in education. London: Routledge.

Department of Basic Education. (2013). Report on the Annual national assessment of 2013 held on 02 December 2013. Pretoria: Department of Basic Education.

Department of Basic Education. (2015). Department of Basic Education on its 2015/16 annual performance \& strategic plans, with Deputy Minister present. Pretoria: Department of Basic Education

Department of Basic Education. (2019). Annual performance plan: DBE strategic plan 2015/162019/20. Pretoria: Department of Basic Education.

Dewey, J. (1933). How we think. Prometheus Books.

Haegele, J. A., Hodge, S. R., \& Shapiro, D. R. (2020). Routledge handbook of adapted physical education. New York: Routledge.

Isaacs, S., Roberts, N., Spencer-Smith, G., \& Brink, S. (2019). Learning through play in grade R classrooms: Measuring practitioners' confidence, knowledge and practice. South African Journal of Childhood Education, 9(1), 1-11. http://dx.doi.org/10.4102/sajce.v9i1.704

Kalogiannakis, M., Ampartzaki, M., Papadakis, S., \& Skaraki, E. (2018). Teaching natural science concepts to young children with mobile devices and hands-on activities. A case study. International Journal of Teaching and Case Studies, 9(2), 171-183. https://doi.org/10.1504/IJTCS.2018.090965

Kalogiannakis, M., Nirgianaki, G. M., \& Papadakis, S. (2018). Teaching magnetism to preschool children: The effectiveness of picture story reading. Early Childhood Education Journal, 46(5), 535-546. https:/ / doi.org/10.1007/s10643-017-0884-4

Lenakakis, L., Howard, L., \& Felekidou, K. (2018). Play and inclusive education. European Journal of Special Education Research, 3(3). https:/ / orcid.org/0000-0001-8914-1384

Mzimela, J. (2016). Exploring the role of teaching using folklore in developing grade $\mathrm{R}$ learners' mother-tongue. Studies of Tribes and Tribals, 14(2), 129-137. https:// doi.org/10.1080/0972639X.2016.11886740

National Association for the Education of Young Children. (2009). Developmentally appropriate practice in early childhood programs serving children from birth through age 8. http://www.naeyc.org/files/naeyc/file/positions/PSDAP.pdf. [Accessed May 22, 2020].

Neha, M., \& Rule, P. N. (2018). Imaginative play and reading development among Grade R learners in KwaZulu-Natal: An ethnographic case study. South African Journal of Childhood Education, 8(1), 1-8. https://doi.org/10.4102/ sajce.v8i1.518.

Nugent, N. (2017). The government and politics of the European Union. Duke University Press.

Parker, R., \& Thomsen, B. S. (2019). Learning through play at school. The LEGO Foundation.

Republic of South Africa. (2015). National integrated early childhood development policy. Government Printers.

Stebler, R., Vogt, F., Wolf, I., Hauser, B., \& Rechsteiner, K. (2013) Play-Based Mathematics in Kindergarten. A Video Analysis of Children's Mathematical Behaviour While Playing a Board Game in Small Groups. Journal für Mathematik-Didaktik, 34, 149175 (2013). https:// doi.org/10.1007/s13138-013-0051-4

UNICEF. (2018). Learning through play: Strengthening learning through play in early childhood education programmes. UNICEF.

United Nations Children's Fund. (2019). A World Ready to Learn: Prioritizing quality early childhood education. UNICEF.

Van Vuuren, C. L., Uitenbroek, D. G., van der Wal, M. F., \& Chinapaw, M. J. (2018) Sociodemographic differences in 10-year time trends of emotional and behavioural problems among adolescents attending secondary schools in 
Amsterdam, the Netherlands. European Child \& Adolescent Psychiatry, 27(12), 16211631.

Vygotsky, L. S. (1978). Mind in society: The development of higher psychological processes. Cambridge, MA: Harvard Institutions of Higher Learning Press. https:// doi.org/10.1002/9781405165518.wbeosn006

Yin, R. K. (2014) Case Study Research: Design and Methods (5th edn.). Thousand Oaks, CA: SAGE. https://doi.org/10.1177\%2F1356389013497081 